\title{
Anti-inflammatory, analgesic, antipyretic and antidiabetic activities of Abutilon hirtum (Lam.) Sweet
}

\author{
Alshymaa A.-R. Gomaa, Mamdouh N. Samy*, Samar Y. Desoukey and Mohamed S. Kamel
}

\begin{abstract}
Background: Many plants of genus Abutilon are traditionally used for treatment of inflammation, bronchitis, piles, gonorrhea, diabetes and fever. Abutilon hirtum is traditionally used to ease the pain of kidney gravel, to treat diarrhoea, cough and toothache, to cure bladder inflammations, wounds and ulcers and as an antipyretic, demulcent, diuretic and mouth wash. The aim of the study is to evaluate the anti-inflammatory, analgesic, antipyretic and antidiabetic effects of the total ethanolic extract and different fractions of Abutilon hirtum (Lam.) Sweet leaves.

Methods: Air dried powder of A. hirtum leaves were extracted using 95\% ethanol and fractionated successively with petroleum ether, chloroform and finally with ethyl acetate. The extracts were concentrated to afford petroleum ether, chloroform, ethyl acetate and aqueous fractions and were investigated for their anti-inflammatory, analgesic, antipyretic and antidiabetic activities using carrageenan-induced paw edema, hot plate, yeast -induced pyrexia and streptozotocininduced hyperglycemia methods, respectively.

Results: The total ethanolic extract and the chloroform fraction exhibited the highest anti-inflammatory activity with a percentage of inhibition 50.8\% which is close to that of indomethacin (52.4\%). The aqueous extract exhibited the maximum analgesic activity (216.6\%) with a rapid onset and a longer duration followed by petroleum ether and chloroform fractions and total extract (189.8, 186.9 and 183.0\%, respectively), which is almost similar to that of acetylsalicylic acid (186.4\%).

The total ethanolic extract showed higher activity compared to the used standard acetylsalicylic acid with a rapid onset (30 min) and a longer duration exhibiting the maximum activity. The crude polysaccharides fraction showed a significant lowering in blood glucose level (81.08\%). The total extract and petroleum ether, chloroform, ethyl acetate and aqueous fractions exhibited a significant anti-diabetic activity after 5 h (47.49, 47.79, 50.04, 49.80 and 46.36\%, respectively) compared with that of metformin (55.45\%).
\end{abstract}

Conclusion: Abutilon hirtum extract and fractions exhibited anti-inflammatory analgesic, antipyretic and antipyretic activities which may be attributed by the presence of active phytoconstituents.

Keywords: Malvaceae, Abutilon hirtum, Anti-inflammatory, Analgesic, Antipyretic, Antidiabetic

\footnotetext{
* Correspondence: mamdouhnabil.2006@yahoo.com

Department of Pharmacognosy, Faculty of Pharmacy, Minia University, Minia 61519, Egypt
} 


\section{Background}

Abutilon is a large genus belonging to family Malvaceae comprises about 150 annual or perennial herbs, shrubs or even small trees native to the tropical and subtropical countries of America, Africa, Asia and Australia [1, 2]. Traditionally, many Abutilon species are used in treatment of inflammation, piles, gonorrhea, bronchitis, diarrhea, cleaning wounds and ulcers [3]. In Malaysia, Abutilon hirtum is used as a poultice to ease the pain of kidney gravel and often mixed with glutinous rice and applied to ulcers. In Thailand, the roots are used against cough and toothache and as an antipyretic. The leaves or flowers are applied to abscesses. In Kenya the fruits are eaten raw, while the leaves are browsed by goats and camels. Water extract of the bark is given to ease childbirth in Kenya and Uganda. In India, traditionally the leaves are used as demulcent, diuretic and to treat diarrhoea. The decoction of the leaves is used as mouth wash and to cure bladder inflammations, wounds and ulcers, since alkaloids are reported from the roots of the plant $[2,4,5]$.

$A$. hirtum possess hepatoprotective, antioxidant and cytotoxic activities [4, 6, 7], in addition to $A$. indicum and $A$. mauritianum are reported to exhibited antiinflammatory, analgesic, antipyretic activities [8-12]. Previous phytochemical investigation of $A$. hirtum led to isolation of flavonoids and phenolic acids [13]. For this reasons the current study evaluate some pharmacological activities of total ethanolic extract and different fractions of $A$. hirtum (Lam.) Sweet leaves including anti-inflammatory, analgesic, antipyretic and antidiabetic effects.

\section{Methods}

\section{Plant material}

The leaves of $A$. hirtum were collected in November 2012 from El-Zohria botanical garden, Cairo, Egypt and identified by Prof. Dr. Mahmoud Abdelhady Hassan Professor of Horticulture, Faculty of Agriculture, Minia University. A voucher sample (Mn-ph-Cog-016) was kept in the Herbarium of Pharmacognosy Department, Faculty of Pharmacy, Minia University, Minia, Egypt.

\section{Preparation of the extract and fractions}

The air dried powdered leaves $(5 \mathrm{Kg}$ ) of $A$. hirtum were extracted with $95 \%$ ethanol and concentrated under reduced pressure. The concentrated ethanolic extract $(550 \mathrm{~g})$ was suspended in the least amount of distilled water, transferred to a separating funnel and partitioned successively with petroleum ether, chloroform and finally with ethyl acetate. The fractions were concentrated under reduced pressure to afford petroleum ether $(150 \mathrm{~g})$, chloroform $(8 \mathrm{~g})$ and ethyl acetate fractions (18 g). The remaining mother liquor was concentrated to give the aqueous fraction $(280 \mathrm{~g})$.

\section{Preparation of the crude polysaccharides}

The concentrated aqueous fraction (280 g) was dissolved in the least amount of distilled water, transferred to a conical flask and polysaccharides allowed to settle by drop wise addition to $1 \mathrm{l}$ of methanol, followed by vigorous shaking, then filtrated using glass Büchner funnel and vacuum pump. The residue (crude polysaccharides) was collected and dried using vacuum drying oven and then kept for further investigation.

\section{Animals}

The animals used in this study include female and male albino rats weighing $200 \pm 50 \mathrm{~g}$ and mice weighing $30 \pm$ $5 \mathrm{~g}$, obtained from animal house of Faculty of Medicine, Assiut University. They were housed under standardized environmental conditions, and fed with standard diet and water. The study was conducted following approval by the Institutional Animal Ethical Committee of Faculty of Pharmacy, Minia University, Minia, Egypt.

\section{Acute toxicity}

The acute toxicity of the total ethanolic extract of Abutilon hirtum leaves was determined by measuring the lethal dose for $50 \%$ of the laboratory animals $\left(\mathrm{LD}_{50}\right)$ [14]. Different dose levels $(1,2,2.5,3$ up to $3.5 \mathrm{~g} / \mathrm{kg}$, p.o) of the total ethanolic extract (suspended in $0.5 \%$ CMC) were orally administrated to different groups of mice $(30 \pm 5 \mathrm{~g}$, each containing six mice). The control group received an equivalent dose of the vehicle $(0.5 \% \mathrm{CMC})$. Both the test and control groups were observed for $24 \mathrm{~h}$ under normal environmental conditions, with free access to food and water.

\section{Anti-inflammatory activity}

The total ethanolic extract and different fractions of $A$. hirtum leaves were evaluated for their anti-inflammatory activity using the carrageenan-induced paw edema method [15]. Female albino rats $(200 \pm 50 \mathrm{~g})$ were randomly divided into seven groups (six animals per group). The specified dose of extract, fractions, and standard drug were suspended in $0.5 \% \mathrm{CMC}$ solution. The control group administered the vehicle (0.5\% CMC solution), while the standard group was given indomethacin orally at a dose level of $8 \mathrm{mg} / \mathrm{kg}$. The total ethanolic extract and different fractions were administrated orally at a dose level of $300 \mathrm{mg} / \mathrm{kg}$ through $2 \mathrm{~h}$ after carrageenan injection $(0.1 \mathrm{ml}, 1 \% \mathrm{w} / v$ in normal saline, s.c.) into the sub-plantar tissue of the right hind paw. The paw thickness $(\mathrm{mm})$ was measured using a vernier caliper at 0 , $0.5,1,2,3,4$ and $5 \mathrm{~h}$ after administration of the tested extract, fractions and standard drug. The percentage 
Table 1 Results of the anti-inflammatory activity of the total ethanolic extract and different fractions of A. hirtum leave using carrageenan induced paw edema method

\begin{tabular}{llllllll}
\hline Group & \multicolumn{7}{l}{ Thickness of the paw $(\mathrm{mm})$} \\
\cline { 2 - 7 } & $0 \mathrm{~h}$ & $30 \mathrm{~min}$ & $1 \mathrm{~h}$ & $2 \mathrm{~h}$ & $3 \mathrm{~h}$ & $4 \mathrm{~h}$ & $5 \mathrm{~h}$ \\
\hline Control (-ve) & $7.37 \pm 0.12$ & $7.37 \pm 0.12$ & $7.5 \pm 0.0$ & $7.62 \pm 0.12$ & $7.62 \pm 0.12$ & $7.87 \pm 0.23$ & $7.87 \pm 0.23$ \\
Total extract (300 mg/kg) & $7.25 \pm 0.14$ & $6.87 \pm 0.12$ & $6.25 \pm 0.14^{* * *}$ & $5.62 \pm 0.23^{* * *}$ & $4.62 \pm 0.23^{* * *}$ & $4.0 \pm 0.20^{* * *}$ & $3.87 \pm 0.12^{* * *}$ \\
Petroleum ether fraction (300 mg/kg) & $7.25 \pm 0.14$ & $7.12 \pm 0.12$ & $6.75 \pm 0.14^{*}$ & $6.37 \pm 0.23^{* *}$ & $5.75 \pm 0.32^{* * *}$ & $5.25 \pm 0.25^{* * *}$ & $4.87 \pm 0.12^{* * *}$ \\
Chloroform fraction (300 mg/kg) & $7.25 \pm 0.14$ & $6.62 \pm 0.23^{*}$ & $6.37 \pm 0.23^{* * *}$ & $5.62 \pm 0.23^{* * *}$ & $4.87 \pm 0.31^{* * *}$ & $4.0 \pm 0.2^{* * *}$ & $3.87 \pm 0.12^{* * *}$ \\
Ethyl acetate fraction (300 mg/kg) & $7.25 \pm 0.14$ & $7.0 \pm 0.0$ & $6.75 \pm 0.14^{*}$ & $6.5 \pm 0.2^{* *}$ & $5.87 \pm 0.12^{* * *}$ & $5.37 \pm 0.37^{* * *}$ & $5.37 \pm 0.37^{* * *}$ \\
Aqueous fraction (300 mg/kg) & $7.12 \pm 0.12$ & $7.12 \pm 0.12$ & $6.75 \pm 0.14^{*}$ & $6.5 \pm 0.2^{* *}$ & $6.0 \pm 0.20^{* * *}$ & $4.87 \pm 0.12^{* * *}$ & $4.75 \pm 0.14^{* * *}$ \\
Indomethacin (8 mg/kg) & $7.25 \pm 0.14$ & $6.5 \pm 0.2^{* *}$ & $6.0 \pm 0.20^{* * *}$ & $5.62 \pm 0.23^{* * *}$ & $5.37 \pm 0.23^{* * *}$ & $4.12 \pm 0.12^{* * *}$ & $3.75 \pm 0.14^{* * *}$ \\
\hline
\end{tabular}

The results are presented as the mean \pm S.E.M Standard error of the mean. Differences with respect to the control group were calculated using the student's T-test $\left({ }^{*} P<0.05,{ }^{* *} P<0.01,{ }^{* * *} P<0.001\right)$

of inhibition of the rat paw edema was calculated as follows [16]:

$$
\% \text { Inhibition }=\frac{\left(\mathrm{ET}_{\mathrm{c}}-\mathrm{ET}_{\mathrm{t}}\right)}{\mathrm{ET}_{\mathrm{c}}} \times 100
$$

$\mathrm{ET}_{\mathrm{c}}$ is Paw edema thickness of control group and $\mathrm{ET}_{\mathrm{t}}$ is Paw edema thickness of treated group.

\section{Analgesic activity}

The total ethanolic extract and different fractions of $A$. hirtum leaves were evaluated for their analgesic activity using hot plate method [17]. Mice $(30 \pm 5 \mathrm{~g})$ were grouped into seven groups (six animals each). The control group administered the vehicle (0.5\% CMC solution) and the standard group administered $100 \mathrm{mg} / \mathrm{kg}$, p.o. of acetylsalicylic acid. The tested extract and different fractions were suspended in $0.5 \% \mathrm{CMC}$ solution and were administrated orally at a dose level of $300 \mathrm{mg} / \mathrm{kg}$. The animals were placed on a hot plate and the temperature of the metal surface was maintained at $54{ }^{\circ} \mathrm{C}$. The time (s) of the response produced by the animal as tail withdrawn, licking paws or jumping due to radiant heat is noted and recorded at $0,0.5,1,2,3,4$ and $5 \mathrm{~h}$ after the administration of the tested extract, fractions and the standard drug. The percentage of thermal pain stimulus protection was calculated according to the following formula [18]:

$$
\begin{aligned}
& \text { \%Protection against thermal stimulus } \\
& =\frac{\left(\mathrm{T}_{\mathrm{t}}-\mathrm{T}_{\mathrm{c}}\right)}{\mathrm{T}_{\mathrm{c}}} \times 100
\end{aligned}
$$

Where $T_{t}$ is the reaction time of treated group and $T_{c}$ is the reaction time of control group.

\section{Antipyretic activity}

The total ethanolic extract and different fractions of $A$. hirtum leaves were tested for their antipyretic activity using yeast-induced pyrexia method $[19,20]$. The test was performed on female albino rats $(200 \pm 50 \mathrm{~g})$ by subcutaneous injection (in the back, below the nape of the neck) of $20 \%$ aqueous suspension of yeast in a dose of $10 \mathrm{ml} / \mathrm{kg}$ to induce pyrexia. The pyretic animals were grouped into seven groups (six animals each). The control group orally administered the vehicle $(0.5 \%$ CMC solution), while the reference group was given acetylsalicylic acid at a dose level of $100 \mathrm{mg} / \mathrm{kg}$, p.o. The tested extract and different fractions were suspended in $0.5 \%$ CMC solution and were administrated orally at a

\begin{tabular}{|c|c|c|c|c|c|c|c|}
\hline \multirow[t]{2}{*}{ Group } & \multicolumn{7}{|c|}{ \% Edema Inhibition } \\
\hline & $\mathrm{Oh}$ & $30 \mathrm{~min}$ & $1 \mathrm{~h}$ & $2 \mathrm{~h}$ & $3 \mathrm{~h}$ & $4 \mathrm{~h}$ & $5 \mathrm{~h}$ \\
\hline Total extract (300 mg/kg) & 1.62 & 6.78 & 16.66 & 26.24 & 24.54 & 33.29 & 50.82 \\
\hline Petroleum ether fraction $(300 \mathrm{mg} / \mathrm{kg})$ & 1.62 & 3.39 & 10.0 & 16.40 & 36.08 & 49.17 & 38.11 \\
\hline Chloroform fraction (300 mg/kg) & 1.62 & 10.17 & 15.06 & 26.24 & 22.96 & 31.76 & 50.82 \\
\hline Ethyl acetate fraction (300 mg/kg) & 1.62 & 5.02 & 10.0 & 14.69 & 21.25 & 38.11 & 31.76 \\
\hline Aqueous fraction (300 mg/kg) & 3.39 & 3.39 & 10.0 & 14.69 & 29.52 & 47.64 & 39.64 \\
\hline Acetylsalicylic acid (100 mg/kg) & 1.62 & 11.80 & 20.0 & 26.24 & 39.37 & 49.17 & 52.35 \\
\hline
\end{tabular}

Table 2 Results representing the percentage of edema inhibition of the total ethanolic extract and different fractions of $A$. hirtum leaves 
Table 3 Results of the analgesic activity of the total ethanolic extract and different fractions of $A$. hirtum leaves in mice using the hot plate method

\begin{tabular}{|c|c|c|c|c|c|c|c|}
\hline Group & Time (sec) & & & & & & \\
\hline & $\mathrm{Oh}$ & $30 \mathrm{~min}$ & $1 \mathrm{~h}$ & $2 \mathrm{~h}$ & $3 \mathrm{~h}$ & $4 \mathrm{~h}$ & $5 \mathrm{~h}$ \\
\hline Control (-ve) & $58 \pm 2.51$ & $60.67 \pm 0.88$ & $62 \pm 2.30$ & $61.33 \pm 1.85$ & $59.33 \pm 2.02$ & $59.5 \pm 1.55$ & $59 \pm 1.47$ \\
\hline Total extract (300 mg/kg) & $60.25 \pm 1.88$ & $57.5 \pm 1.32$ & $94.25 \pm 4.42^{* * *}$ & $94 \pm 5^{* * *}$ & $152.7 \pm 3.28^{* * *}$ & $159.8 \pm 4.19^{* * *}$ & $167 \pm 3.34^{* * *}$ \\
\hline Petroleum ether fraction $(300 \mathrm{mg} / \mathrm{kg})$ & $59 \pm 2.48$ & $60.75 \pm 1.93$ & $72.25 \pm 3.98$ & $97 \pm 1.68^{* * *}$ & $138.3 \pm 7.51^{* * *}$ & $167.3 \pm 2.72^{* * *}$ & $171 \pm 1^{* * *}$ \\
\hline Chloroform fraction (300 mg/kg) & $64.33 \pm 1.76$ & $68.67 \pm 3.84$ & $75.5 \pm 5.31$ & $94.33 \pm 4.66^{* * *}$ & $112 \pm 4.20^{* * *}$ & $156.7 \pm 7.83^{* * *}$ & $169.3 \pm 5.72^{* * *}$ \\
\hline Ethyl acetate fraction (300 mg/kg) & $52.25 \pm 3.19$ & $55 \pm 0.57$ & $57.25 \pm 1.75$ & $57.75 \pm 3.49$ & $63.5 \pm 2.53$ & $59.25 \pm 1.93$ & $58.75 \pm 2.95$ \\
\hline Aqueous fraction (300 mg/kg) & $62.5 \pm 2.32$ & $75.33 \pm 2.84^{* *}$ & $86 \pm 4.91^{* *}$ & $94.75 \pm 2.72^{* * *}$ & $108 \pm 6.24^{* * *}$ & $155.3 \pm 3.70^{* * *}$ & $186.8 \pm 5.51^{* * *}$ \\
\hline Acetylsalicylic acid (100 mg/kg) & $56.25 \pm 1.70$ & $67.5 \pm 3.61$ & $71.5 \pm 3.66$ & $79 \pm 2.48^{* *}$ & $93.67 \pm 4.37^{* * *}$ & $131.7 \pm 5.20^{* * *}$ & $169 \pm 7.37^{* * *}$ \\
\hline
\end{tabular}

The results are presented as the mean \pm S.E.M Standard error of the mean. Differences with respect to the control group were calculated using the student's T-test $\left({ }^{*} P<0.05,{ }^{* *} P<0.01,{ }^{* * *} P<0.001\right)$

dose level of $300 \mathrm{mg} / \mathrm{kg}$ through $2 \mathrm{~h}$ after yeast injection. The rectal temperature of each animal was recorded by inserting a thermometer $2 \mathrm{~cm}$ into the rectum at $0,0.5,1$, 2, 3, 4 and $5 \mathrm{~h}$ after administration of the tested extract, fractions and the reference drug.

\section{Anti-diabetic activity}

The antidiabetic activity of the total ethanolic extract and different fractions of $A$. hirtum leaves was evaluated using streptozotocin-induced hyperglycemia method $[21,22]$. The test was performed on adult male albino rats $(200 \pm 50 \mathrm{~g})$ by intraperitoneal injection of streptozotocin $(80 \mathrm{mg} / \mathrm{kg})$. Blood glucose level was measured after 3 days up to one week for assessment of hyperglycemia. Rats with blood glucose level above $(200 \mathrm{mg} / \mathrm{dl})$ were considered to be diabetic and were used in this study. The diabetic rats were divided into eight groups (six rats each). The control group was administered the vehicle $(0.5 \% \mathrm{CMC}$ solution), while the standard group was given of $150 \mathrm{mg} / \mathrm{kg}$ p.o metformin. The tested extract and different fractions were suspended in $0.5 \%$ CMC solution and were orally administrated at a dose level of $300 \mathrm{mg} / \mathrm{kg}$. Blood glucose levels were measured at intervals of 0 (fasting), $0.5,1,2,3,4$ and $5 \mathrm{~h}$ by collecting blood samples from the tail vein (caudal vein). The percentage of change in blood glucose level was calculated by the following formula [23, 24]:

$$
\text { \%lowering blood glucose level }=\frac{\left(\mathrm{W}_{\mathrm{c}}-\mathrm{W}_{\mathrm{t}}\right)}{\mathrm{W}_{\mathrm{c}}}
$$

Where $W_{t}$ is the blood glucose concentrations of treated group and $W_{c}$ is the blood glucose concentrations of control group.

\section{Statistical analysis}

Results of all biological studies were expressed as means \pm S.E.M. One-way analysis of variance (ANOVA) followed by Dunnett's test was used to determine significance when compared to the control group. $p$ values less than 0.05 , 0.01 , and 0.001 were considered significant $\left({ }^{*} p<0.05\right.$, $\left.{ }^{* * *} p<0.01,{ }^{* * * * *} p<0.001\right)$. Graph Pad Prism 5 was used for statistical calculations (Graph pad Software, San Diego California, USA).

\section{Results \\ Acute Toxicity}

There was no mortality or signs of toxicity up to $3 \mathrm{~g} / \mathrm{kg}$ of the total ethanolic extract of $A$. hirtum leaves.

Table 4 Results representing the percentage of protection against thermal stimulus of the total ethanolic extract and different fractions of $A$. hirtum leaves

\begin{tabular}{|c|c|c|c|c|c|c|c|}
\hline \multirow[t]{2}{*}{ Group } & \multicolumn{7}{|c|}{$\%$ Protection } \\
\hline & $\mathrm{Oh}$ & $30 \mathrm{~min}$ & $1 \mathrm{~h}$ & $2 \mathrm{~h}$ & $3 \mathrm{~h}$ & $4 \mathrm{~h}$ & $5 \mathrm{~h}$ \\
\hline Total extract (300 mg/kg) & 3.87 & -5.22 & 52.01 & 53.26 & 157.37 & 168.57 & 183.05 \\
\hline Petroleum ether fraction (300 mg/kg) & 1.72 & 0.13 & 16.53 & 58.16 & 133.10 & 181.17 & 189.83 \\
\hline Chloroform fraction $(300 \mathrm{mg} / \mathrm{kg})$ & 10.91 & 13.18 & 21.77 & 53.80 & 88.77 & 163.36 & 186.94 \\
\hline Ethyl acetate fraction (300 mg/kg) & -9.91 & -9.34 & -7.66 & -5.83 & 7.02 & -0.42 & -0.42 \\
\hline Aqueous fraction (300 mg/kg) & 7.75 & 24.16 & 38.70 & 54.49 & 82.03 & 161.00 & 216.61 \\
\hline Acetylsalicylic acid (100 mg/kg) & -3.10 & 11.25 & 15.32 & 28.81 & 57.87 & 121.34 & 186.44 \\
\hline
\end{tabular}


Table 5 Results of the antipyretic activity of the total ethanolic extract and different fractions of A. hirtum leaves on yeast-induced pyrexia method

\begin{tabular}{lccccccc}
\hline Group & \multicolumn{7}{l}{ Rectal temperature $\left({ }^{\circ} \mathrm{C}\right)$} \\
\hline & $0 \mathrm{~h}$ & $30 \mathrm{~min}$ & $1 \mathrm{~h}$ & $2 \mathrm{~h}$ & $3 \mathrm{~h}$ & $4 \mathrm{~h}$ & $5 \mathrm{~h}$ \\
Control (-ve) & $38.73 \pm 0.08$ & $38.85 \pm 0.02$ & $38.85 \pm 0.05$ & $38.88 \pm 0.02$ & $39.55 \pm 0.13$ & $39.9 \pm 0.04$ & $39.98 \pm 0.08^{* * *}$ \\
Total extract (300 mg/kg) & $38.63 \pm 0.10$ & $38.2 \pm 0.07^{* * *}$ & $37.3 \pm 0.09^{* * *}$ & $36.35 \pm 0.06$ *** & $36.23 \pm 0.04^{* * *}$ & $36.13 \pm 0.04^{* * *}$ & $36.05 \pm 0.02^{* * *}$ \\
Petroleum ether fraction (300 mg/kg) & $38.68 \pm 0.08$ & $38.23 \pm 0.12^{* * *}$ & $38.15 \pm 0.02^{* * *}$ & $37.33 \pm 0.10^{* * *}$ & $37.4 \pm 0.17^{* * *}$ & $37.13 \pm 0.07^{* * *}$ & $37.1 \pm 0.04^{* * *}$ \\
Chloroform fraction (300 mg/kg) & $38.7 \pm 0.09$ & $38.73 \pm 0.04$ & $38.63 \pm 0.04$ & $38.5 \pm 0.04^{* * *}$ & $38.43 \pm 0.04^{* * *}$ & $38.48 \pm 0.04^{* * *}$ & $38.5 \pm 0.04^{* * *}$ \\
Ethyl acetate fraction (300 mg/kg) & $38.75 \pm 0.09$ & $38.5 \pm 0.04^{*}$ & $38.2 \pm 0.07^{* * *}$ & $37.63 \pm 0.06^{* * *}$ & $37.55 \pm 0.06^{* * *}$ & $37.2 \pm 0.04^{* * *}$ & $37.05 \pm 0.02^{* * *}$ \\
Aqueous fraction (300 mg/kg) & $38.73 \pm 0.06$ & $38.43 \pm 0.08^{* *}$ & $38 \pm 0.13^{* * *}$ & $37.48 \pm 0.02^{* * *}$ & $37.43 \pm 0.04^{* * *}$ & $37.25 \pm 0.11^{* * *}$ & $37.13 \pm 0.07^{* * *}$ \\
Acetylsalicylic acid (100 mg/kg) & $38.78 \pm 0.07$ & $38.48 \pm 0.06^{* *}$ & $37.7 \pm 0.16^{* * *}$ & $37.43 \pm 0.04^{* * *}$ & $37.2 \pm 0.04^{* * *}$ & $37.2 \pm 0.07^{* * *}$ & $37.15 \pm 0.02^{* * *}$
\end{tabular}

The results are presented as the mean \pm S.E.M Standard error of the mean. Differences with respect to the control group were calculated using the student's T-test $\left(* P<0.05, * * P<0.01,{ }^{* * *} P<0.001\right)$

\section{Anti-inflammatory activity}

The tested fractions and total extract exhibited a significant decrease in the paw edema induced by carrageenan especially after $2 \mathrm{~h}$ from the beginning of the experiment (Table 1 and 2 and Additional file 1). After $2 \mathrm{~h}$, both the total ethanolic extract and the chloroform fraction exhibited the same percentage of inhibition $(26.2 \%)$ as that of the indomethacin, whereas the following hours showed results quite higher than the standard. After $5 \mathrm{~h}$ both the total ethanolic extract and the chloroform fraction exhibited the highest anti-inflammatory activity with a percentage of inhibition $50.8 \%$ which is close to that of indomethacin (52.4\%). The petroleum ether and the aqueous fractions showed a mild inhibition of the inflammation that was increased by time to be 38.1 and $39.6 \%$ after $5 \mathrm{~h}$, respectively. On the other hand, the least activity was shown by the ethyl acetate fraction through the $5 \mathrm{~h}$ of the experiment (31.8\%).

\section{Analgesic activity}

The total ethanolic extract and different fractions of $A$. hirtum leaves (Table 3 and 4 and Additional file 2) demonstrated that the total ethanolic extract and all fractions exhibited potent analgesic activity except the ethyl acetate fraction. One hour from the beginning of the experiment both the total ethanolic extract and aqueous fraction showed the highest percentage of protection against thermal stimulus (52.0 and $38.7 \%$, respectively) in comparison with acetylsalicylic acid (15.3\%). Furthermore, after $2 \mathrm{~h}$ the petroleum ether and chloroform fractions exhibited effects higher than acetylsalicylic acid. The aqueous extract exhibited the maximum analgesic activity (216.6\%) with a rapid onset and a longer duration followed by petroleum ether and chloroform fractions and total extract (189.8, 186.9 and $183.0 \%$, respectively), which is almost similar to that of acetylsalicylic acid (186.4\%). On the other hand, the ethyl acetate fraction showed no analgesic activity throughout the experiment time.

\section{Antipyretic activity}

The total ethanolic extract and different fractions of A. hirtum leaves revealed that the total ethanolic extract and most of fractions exhibited a significant $(P<0.001)$ antipyretic activity up to $5 \mathrm{~h}$ (Table 5 and

Table 6 Results of anti-diabetic activity of the total ethanolic extract and different fractions of A. hirtum leaves on streptozotocin-induced hyperglycemia

\begin{tabular}{|c|c|c|c|c|c|c|c|}
\hline Group & Blood glucos & e level $(\mathrm{mg} / \mathrm{dl}$ & & & & & \\
\hline & $\mathrm{O}$ h (fasting) & $30 \mathrm{~min}$ & $1 \mathrm{~h}$ & $2 \mathrm{~h}$ & $3 \mathrm{~h}$ & $4 \mathrm{~h}$ & $5 \mathrm{~h}$ \\
\hline Control (-ve) & $203.3 \pm 2.32$ & $201.8 \pm 1.79$ & $201.3 \pm 1.49$ & $202.8 \pm 1.93$ & $207.3 \pm 1.93$ & $208.5 \pm 1.70^{* * *}$ & $208.8 \pm 2.78^{* * *}$ \\
\hline Total extract (300 mg/kg) & $202.3 \pm 1.79$ & $201.8 \pm 1.25$ & $184 \pm 2.64$ & $150 \pm 2.08^{* * *}$ & $145.5 \pm 2.75^{* * *}$ & $123.3 \pm 3.32^{* * *}$ & $109 \pm 4.54^{* * *}$ \\
\hline Petroleum ether fraction (300 mg/kg) & $206.3 \pm 1.70$ & $199 \pm 5.05$ & $183.5 \pm 4.34$ & $158.5 \pm 4.69^{* * *}$ & $142.5 \pm 3.5^{* * *}$ & $129.3 \pm 4.90^{* * *}$ & $109 \pm 5.35^{* * *}$ \\
\hline Chloroform fraction (300 mg/kg) & $206.8 \pm 2.32$ & $195.8 \pm 3.63$ & $174.8 \pm 2.72^{* *}$ & $149 \pm 4.69^{* * *}$ & $141.5 \pm 3.40^{* * *}$ & $124.5 \pm 4.57^{* * *}$ & $104.3 \pm 3.03^{* * *}$ \\
\hline Ethyl acetate fraction $(300 \mathrm{mg} / \mathrm{kg})$ & $205 \pm 2.85$ & $202.8 \pm 2.62$ & $161.3 \pm 5.48^{* * *}$ & $150.5 \pm 5.12^{* * *}$ & $142 \pm 3.87^{* * *}$ & $113.5 \pm 3.86^{* * *}$ & $104.8 \pm 2.01^{* * *}$ \\
\hline Aqueous fraction $(300 \mathrm{mg} / \mathrm{kg}$ ) & $205.3 \pm 3.56$ & $204.3 \pm 3.63$ & $181.3 \pm 5.51^{*}$ & $160 \pm 4.93^{* * *}$ & $153.5 \pm 2.63^{* * *}$ & $138.5 \pm 3.5^{* * *}$ & $112 \pm 5.5^{* * *}$ \\
\hline Crude polysaccharides (300 mg/kg) & $207.3 \pm 3.77$ & $199.8 \pm 1.25$ & $172.7 \pm 6.83^{* *}$ & $96.3 \pm 6.36^{* * *}$ & $87.25 \pm 6.30^{* * *}$ & $72.25 \pm 5.28^{* * *}$ & $39.5 \pm 2.5^{* * *}$ \\
\hline Metformin (150 mg/kg) & $204 \pm 2.64$ & $199 \pm 1.35$ & $166.5 \pm 6.70^{* * *}$ & $137.8 \pm 3.19^{* * *}$ & $126.5 \pm 2.21^{* * *}$ & $113 \pm 4.54^{* * *}$ & $93 \pm 4.08^{* * *}$ \\
\hline
\end{tabular}

The results are presented as the mean \pm S.E.M Differences with respect to the control group were calculated using the student's T- test ${ }^{*} P<0.05$, $\left.{ }^{* *} P<0.01,{ }^{* * *} P<0.001\right)$ 
Table 7 Results of the effect of the total ethanolic extract and different fractions of A. hirtum leaves on the percentage of lowering blood glucose level on diabetic rats

\begin{tabular}{|c|c|c|c|c|c|c|c|c|}
\hline \multirow[t]{2}{*}{ Group } & \multirow{2}{*}{$\begin{array}{l}\text { Dose } \\
\mathrm{mg} / \mathrm{kg}\end{array}$} & \multicolumn{7}{|c|}{ Percentage of lowering blood glucose level (\%) } \\
\hline & & $\mathrm{Oh}$ & $30 \mathrm{~min}$ & $1 \mathrm{~h}$ & $2 \mathrm{~h}$ & $3 \mathrm{~h}$ & $4 \mathrm{~h}$ & $5 \mathrm{~h}$ \\
\hline Total extract & 300 & 0.34 & 0.0 & 0.0 & 26.03 & 29.81 & 40.86 & 47.79 \\
\hline Petroleum ether fraction & 300 & -1.62 & 1.38 & 0.27 & 21.84 & 31.25 & 37.98 & 47.79 \\
\hline Chloroform fraction & 300 & -1.87 & 2.97 & 5.0 & 26.52 & 31.74 & 40.28 & 50.04 \\
\hline Ethyl acetate fraction & 300 & -0.98 & -0.49 & 12.33 & 25.78 & 31.50 & 45.56 & 49.80 \\
\hline Aqueous fraction & 300 & -1.13 & -1.23 & 1.46 & 21.10 & 25.95 & 33.57 & 46.36 \\
\hline Crude polysaccharides & 300 & -2.11 & 0.99 & 6.14 & 52.51 & 57.91 & 65.34 & 81.08 \\
\hline Metformin & 150 & -0.49 & 1.38 & 9.51 & 32.05 & 38.97 & 45.80 & 55.45 \\
\hline
\end{tabular}

Additional file 3). The total ethanolic extract showed higher activity compared to the used standard acetylsalicylic acid with a rapid onset $(30 \mathrm{~min})$ and a longer duration exhibiting the maximum activity. After $4 \mathrm{~h}$ from the beginning of the experiment the petroleum ether, ethyl acetate and aqueous fractions showed the same effect as that of acetylsalicylic acid that lasted up to $5 \mathrm{~h}$. The least activity was shown by the chloroform fraction where no significant effect was observed throughout the $5 \mathrm{~h}$ of the experiment.

\section{Anti-diabetic activity}

The total ethanolic extract and all fractions showed a significant $(* * * P<0.001)$ decrease in blood glucose level (Table 6 and 7 and Additional file 4) especially after $2 \mathrm{~h}$ from oral administration and their effects were maintained for $5 \mathrm{~h}$. The crude polysaccharides fraction showed a significant lowering in blood glucose level (52.51\%) after $2 \mathrm{~h}$ which increased by time after $3 \mathrm{~h}$ (57.91\%), $4 \mathrm{~h}(65.34 \%)$ and $5 \mathrm{~h}$ (81.08\%). The blood glucose levels of the mice were reduced significantly when administered total extract and petroleum ether, chloroform, ethyl acetate and aqueous after $5 \mathrm{~h}$, where the percent of lowering blood glucose levels were 47.49, 47.79, $50.04,49.80$ and $46.36 \%$, respectively, compared with that of metformin $(55.45 \%)$.

\section{Discussion}

$\mathrm{LD}_{50}$ of the total ethanolic extract is $3 \mathrm{~g} / \mathrm{Kg}$ indicating its wide margin of safety. Hence, the chosen experimental dose of the total extract and different fractions is $300 \mathrm{mg} / \mathrm{kg}$ which is one-tenth of the lethal dose $(3 \mathrm{~g} / \mathrm{kg})$ [25]. The total ethanolic extract and the chloroform fraction exhibited the highest anti-inflammatory activity compared to indomethacin and the potent antipyretic activity of the total ethanolic extract may be attributed to their content of sterols and flavonoids which were reported to have antiinflammatory and antipyretic activities [12, 26, 27]. Also, many mechanisms were proved for the anti-inflammatory activity of flavonoids as inhibition of cyclooxygenase and 5-lipoxygenase pathways, inhibition of eicosanoid biosynthesis, besides its ability to inhibit neutrophil degranulation [28]. Furthermore, the significant of the total ethanolic extract and aqueous fraction may be attributed to their high content of flavonoids and flavonoidal glycosides, in addition to sterols which were reported to have analgesic activity [27]. The total ethanolic extract and different fractions exhibited a potent anti-diabetic effect and the crude polysaccharides was found to have the highest antidiabetic activity from the first hour till the third hour followed by a sever hypoglycemia after $4 \mathrm{~h}$. This hypoglycemic effect may be attributed to a decrease in blood glucose level or inhibition of glucose absorption [29], an increase in the insulin secretion level, reduced insulin metabolism, through remediating destruction of pancreatic islets and damage of pancreatic $\beta$-cells $[30,31]$.

\section{Conclusion}

The present study revealed that total ethanolic extract and different fractions of $A$. hirtum leaves exhibited antiinflammatory, analgesic, antipyretic and antidiabetic activities which are in accordance with folk medicine of many Abutilon plants, inaddition to the wide margin of safety of the total ethanolic extract which may assist to develop new drugs from natural source.

\section{Additional files}

Additional file 1: Diagram representing the effects of the total ethanolic extract and different fractions of $A$. hirtum leaves on paw thickness using carrageenan - induced paw edema. (DOCX 177 kb)

Additional file 2: Diagram representing the analgesic activity of the total ethanolic extract and different fractions of $A$. hirtum leaves. (DOCX $157 \mathrm{~kb}$ )

Additional file 3: Diagram representing the effects of the total ethanolic extract and different fractions of $A$. hirtum leaves on yeastinduced pyrexia. (DOCX $172 \mathrm{~kb}$ )

Additional file 4: Diagram representing the effects of the total ethanolic extract and different fractions of $A$. hirtum leaves on streptozotocin-induced hyperglycemia in rats. (DOCX $173 \mathrm{~kb}$ ) 


\section{Abbreviations}

A. hirtum: Abutilon hirtum; A. indicum: Abutilon indicum; A mauritianum: Abutilon mauritianum; CMC: Carboxy methyl cellulose; $\mathrm{LD}_{50}$ : Lethal dose 50; p.o.: Taken orally; s.c: Subcutaneous

\section{Authors' contributions}

AAG performed all of the experiments in the laboratory and data collection, analysis, graphical representation and interpretation. MNS did critical statistical analysis and wrote the manuscript draft. Critical revision of the article was done by SYD. Conception, experiment design, overall monitoring and final approval of the article was done by MSK. All authors read and approved the final manuscript.

\section{Competing interests}

The authors declare that they have no competing interests.

Received: 21 July 2017 Accepted: 6 March 2018

/ Published online: 18 April 2018

\section{References}

1. Arbat AA. Pharmacognostic studies of stem of Abutilon pannosum (Forst F.). Biosci Discov. 2012;3:317-20.

2. Brink M, Dako EG. Plant Resources of Tropical Africa 16. Fibres. Wageningen, Netherlands: Prota Foundation; 2012. p. 25.

3. Khadabadi SS, Bhajipale NS. A review on some important medicinal plants of Abutilon spp. Res J Pharm Biol. Chem Sci. 2010;1:718-29.

4. Wesley SP, Devi CB, Moin S, Shibu SB. In vitro phytochemical screening, free radical scavenging activity and anticancer activity of Abutilon hirtum (Lam.) Sweet (Malvaceae). Int J PharmTech Res. 2013;5:155-61.

5. Gomaa AA, Samy MN, Desoukey SY, Kamel MS. Pharmacognostical studies of leaf, stem, root and flower of Abutilon hirtum (Lam.) Sweet. Int J Pharmacogn Phytochem Res. 2016;8:199-216.

6. Srinivas RK, Sanjeeva KA, Gnananath K, Ganapaty S. Hepatoprotective potential of Abutilon hirtum Sweet leaves in carbon tetrachloride induced hepatotoxicity. Asian J Biomed Pharm Sci. 2011;1:26-31.

7. Kassem HA. Investigation of lipids, mucilage and cytotoxic activity of Abutilon hirtum (Lam.) Sweet grown in Egypt. Bull Fac Pharm. Cairo Univ. 2001;39:156-9.

8. Saraswathi R, Upadhyay L, Venkatakrishnan R, Meera R, Devi P. Phytochemical investigation, analgesic and anti- inflammatory activity of Abutilon indicum linn. Int J Pharm Pharm Sci. 2011;3:154-6.

9. Sharma A, Sharma RA, Singh H. Phytochemical and Pharmacological Profile of Abutilon indicum L. Sweet: A Review. Int J Pharm Sci Rev Res. 2013;20:120-7.

10. Kaladhar DK, Saranya SK, Vadlapudi V, Yarla NS. Evaluation of anti-inflammatory and anti-proliferative activity of Abutilon indicum L. plant ethanolic leaf extract on lung cancer cell line A 549 for system network studies. Cancer Sci Ther. 2014:6:195-201.

11. Kushwaha SK, Dashora A, Patel JR, Kori ML. Antinociceptive and anti-inflammatory activities of quercetin isolated from ethanolic extract of Abutilon indicum L. Novus Nat Sci Res. 2014;3:8-15.

12. Akapa TC, Kehinde AO, Beatrice OO, Olajide OJ. Antipyretic activity of Abutilon mauritianum (Jacq.) roots in Wistar rats. Int J Pharm Sci Res. 2014;5:42-6.

13. Kassem HA. Study of polyphenolic components and macro- and micromorphological characters of Abutilon hirtum (Lam.) Sweet. Bull Fac Pharm. Cairo Univ. 2007:45:173-83.

14. Akhila JS, Deepa S, Alwar MC. Acute toxicity studies and determination of median lethal dose. Current Sci. 2007;93:917-20.

15. Winter CA, Risley GA, Nuss GW. Carrageenan induced edema in hind paw of the rat as an assay for inflammatory drugs. Proc Soc Exp Biol Med. 1962;111:544-7.

16. Sudjarwo AS. The Potency of piperine as anti-inflammatory and analgesic in rats and mice. Folia Medica Indonesiana. 2005;41:190-4.

17. Hosseinzadeh H, Ramezani M, Salmani G. Antinociceptive, anti-inflammatory and acute toxicity effects of Zataria multiflora Boiss extracts in mice and rats. J Ethnopharmcol. 2000;73:379-85.

18. Magaji M, Anuka J, Abdu-Aguye I, Yaro A, Hussaini I. Preliminary studies on anti-inflammatory and analgesic activities of Securinega virosa (Euphorbiaceae) in experimental animal models. J Med Plants Res. 2008;2:39-44.

19. Adams SS, Hebborn P, Nicholson JS. Some aspects of the pharmacology of ibufenac, a non-steroidal anti-inflammatory agent. J Pharm Pharmacol. 1968; 20:305-12.
20. Panthong A, Kanjanapoth D, Taesotikul T, Wongcome T, Reutrakul V. Anti-inflammatory and antipyretic properties of Clerodendrum petasites $S$. Moore J Ethanopharmacol. 2003;85:151-6.

21. Gruber HE, Schedl HP, Osborne JW. Alterations in islet cell ultrastructure following streptozotocin-induced diabetes in the rat. ActaDiabetologia Latina. 1980;17:213-23.

22. Peungvicha $P$, Thirawarapan SS, Temsiririrkkul $R$, Watanabe $H$, Prasain JK, Kadota S. Hypoglycemic effect of the water extract of Piper sarmentosum in rats. J Ethnopharmcol. 1998:60:27-32.

23. Tanko Y, Okasha MA, Saleh IA, Mohammed A, Yerima M, Yaro AH, Isa Al. Anti-diabetic effect of ethanolic flower extracts of Newbouldia laevis (Bignoniaceae) on blood glucose levels of streptozocin-induced diabetic wistar rats. Res J Med Sci. 2008;2:62-5.

24. Oany AR, Al Siddikey A, Hossain MU, Islam R, Emran A-A. A preliminary evaluation of cytotoxicity, antihyperglycemic and antinociceptive activity of Polygonum hydropiper L. ethanolic leaf extract. Clinical Phytoscience. 2016;2:2.

25. Prasad PJ. Conceptual Pharmacology. India: University Press Private limited; 2010. p. 55.

26. Owoyele BV, Oguntoye SO, Dare K, Ogunbiyi BA, Aruboula EA, Soladoye AO. Analgesic, anti-inflammatory and antipyretic activities from flavonoid fractions of Chromolaena odorata. J Med Plants Res. 2008;2:219-25.

27. Niazi J, Gupta V, Chakarborty P, Kumar P. Anti-inflammatory and antipyretic activity of aleuritis moluccana leaves. Asian J Pharm Clinical Res. 2010;3:35-7.

28. Nijveldt RJ, Nood EV, Hoorn DE, Boelens PG, Norren KV, Paul AL. Flavonoids: a review of probable mechanisms of action and potential applications. Amer J Clinical Nutri. 2001;74:418-25.

29. Krisanapun C, Lee S, Peungvicha P, Temsiririrkkul R, Baek SJ. Antidiabetic activities of Abutilon indicum (L.) Sweet are mediated by enhancement of adipocyte differentiation and activation of the GLUT1 promoter. Evidence-Based Complement Alternat Med. 2011;2011:1-9.

30. Chen X, Jin J, Tang J, Wang Z, Wang J, Jin L, Lu J. Extraction, purification, characterization and hypoglycemic activity of a polysaccharide isolated from the root of Ophiopogon japonicas. Carbohydr Polymers. 2011;83:749-54.

31. Li SP, Zhang GH, Zeng Q, Huang ZG, Wang YT, Dong TT, Tsim KW. Hypoglycemic activity of polysaccharide, with antioxidation, isolated from cultured Cordyceps mycelia. Phytomedicine. 2006;13:428-33.

\section{Submit your manuscript to a SpringerOpen ${ }^{\circ}$ journal and benefit from:}

- Convenient online submission

- Rigorous peer review

- Open access: articles freely available online

- High visibility within the field

Retaining the copyright to your article

Submit your next manuscript at springeropen.com 